\title{
The Predictability of Annual Evapotranspiration and Runoff in Humid and Nonhumid Catchments over China: Comparison and Quantification ${ }^{\mathscr{O}}$
}

\author{
TINGTING WANG \\ Key Laboratory of Water Cycle and Related Land Surface Processes, Institute of Geographic Science and \\ Natural Resources Research, Chinese Academy of Sciences, and College of Resources and Environment, \\ University of Chinese Academy of Sciences, Beijing, China
}

\section{FUBAO SUN}

Key Laboratory of Water Cycle and Related Land Surface Processes, Institute of Geographic Science and Natural Resources Research, Chinese Academy of Sciences, and College of Resources and Environment, University of Chinese Academy of Sciences, Beijing, and Ecology Institute of Qilian Mountain, Hexi University, Zhangye City, Gansu Province, and Center for Water Resources Research, Chinese Academy of Sciences, Beijing, China

\section{WEE HO LIM}

Key Laboratory of Water Cycle and Related Land Surface Processes, Institute of Geographic Science and Natural Resources Research, Chinese Academy of Sciences, Beijing, China, and Environmental Change Institute, University of Oxford, Oxford, United Kingdom

\section{Hong Wang, Wenbin LiU, And Changming LiU}

\author{
Key Laboratory of Water Cycle and Related Land Surface Processes, Institute of Geographic Science and \\ Natural Resources Research, Chinese Academy of Sciences, Beijing, China
}

(Manuscript received 25 August 2017, in final form 8 January 2018)

\begin{abstract}
Climate change and its potential threats on water security call for reliable predictions of evapotranspiration (ET) and runoff $Q$ at different time scales, but current knowledge of the differences in their predictability between humid and nonhumid regions is limited. Based on spatially distributed catchments in China, the authors characterized their predictability and provided plausible explanations. Using the Budyko framework, it was confirmed that annual ET is predictable in nonhumid regions but less predictable in humid regions, and annual $Q$ is predictable in humid regions but less reliable in nonhumid regions. The main cause of the varied predictability lies in the variation of water storage change $\Delta S$ in the water balance equation. It affects both the estimation and the variability of $Q$ in nonhumid catchments more than that in humid catchments, which increases the challenge of predicting annual $Q$ in nonhumid regions, while the opposite effect occurs in annual ET prediction between humid and nonhumid catchments. Moreover, the differences between the controlling factors of ET variability in different regions add more differences in their predictability. The dominant control of precipitation makes it easy to predict annual ET in nonhumid regions. By contrast, precipitation, potential evaporation, and their covariance take considerable effort to determine annual ET variations, which leads to less reliable ET estimation and predictability in humid catchments. Therefore, one can accurately predict annual ET in nonhumid catchments and $Q$ in humid catchments based on commonly used hydrological models. With proper consideration of $\Delta S$, the predictability of annual ET and $Q$ in both humid and nonhumid catchments can be improved.
\end{abstract}

Supplemental information related to this paper is available at the Journals Online website: https://doi.org/10.1175/JHM-D-170165.s1.

Corresponding author: Fubao Sun, sunfb@igsnrr.ac.cn

\section{Introduction}

Reliable prediction of evapotranspiration (ET) and runoff $Q$ provides invaluable informational support for the operation of hydropower stations (Kistenmacher and Georgakakos 2015; Rheinheimer et al. 2016), sustainable 
management of water resources (Bierkens 2015; Oki and Kanae 2006), and protection of the ecological environment (Bierkens 2015; Donohue et al. 2010). The increasing imbalance between water supply and demand calls for more attention on the advancement of annual ET and $Q$ prediction in a changing climate (Kumar 2011; Vogel et al. 2015). Above all, anticipation of climate change-induced hydrological variability and the adverse impact on human society is fueling a greater demand for hydrological models with decent predictive capacity (Wagener et al. 2010). In addition, limited observations of annual $Q$ and ET in ungauged catchments (Sivapalan et al. 2003) means that reliable estimates of hydrological components are needed to predict ET and $Q$ for all practical purposes.

The previous ET studies at annual time scales are focused mainly on nonhumid regions but much less on humid regions. Based on the commonly applied Budyko equations (Budyko 1963; Budyko 1974; Fu 1981), ET shows a clear feature of water control in nonhumid regions and energy control in humid regions (Carmona et al. 2016; Gudmundsson et al. 2016; Kumar et al. 2016; Li et al. 2013; Zhang et al. 2004). Reliable estimation of annual ET has been achieved in nonhumid regions using the Budyko equations (Yang et al. 2007; Zhang et al. 2004) as well as approaches like the remote sensing output (Y. Q. Zhang et al. 2008) and hydrological models (Sankarasubramanian and Vogel 2002; Y. Q. Zhang et al. 2008). High $R^{2}$ of greater than 0.7 has been obtained when comparing the modeled ET using Fu's (1981) type of Budyko equation, Zhang et al.'s (2001) type of Budyko equation, remote sensing outputs (Leuning et al. 2008; Y. Q. Zhang et al. 2008), and hydrological models (Chiew et al. 2002) against ET from a water balance equation $\left(\mathrm{ET}_{\mathrm{wb}}\right)$ in arid regions of Australia. This $R^{2}$ could be much higher than 0.9 when evaluated in arid and semiarid catchments over China (Yang et al. 2007). Further analysis of how climate change and anthropogenic activities are affecting annual ET were conducted with respect to vegetation (Donohue et al. 2007, 2012) and water storage changes $\Delta S$ (Gentine et al. 2012; Istanbulluoglu et al. 2012). However, the ET estimation was less successful in humid regions using these approaches when compared with $\mathrm{ET}_{\mathrm{wb}}$ (Y. Q. Zhang et al. 2008). The trends of modeled ET using the Budyko equation and remote sensing outputs do not match the trend of $\mathrm{ET}_{\mathrm{wb}}$, showing that these approaches are, as yet, not sufficiently accurate to explain trends in ET for humid regions (Y. Q. Zhang et al. 2008). Furthermore, the effort of taking $\Delta S$ into account has been made to improve the estimation of ET in humid regions (Chen et al. 2013; Freund and Kirchner 2017) at intra-annual time scales, but limited research has reported improvement at an annual time scale.
The predictability of annual $Q$ is just the opposite of ET, which is more reliable with higher $R^{2}$ in humid regions based on the commonly used Budyko equations and hydrological models (Wang and Alimohammadi 2012; Yang et al. 2007; L. Zhang et al. 2008). One possible explanation is that the change in precipitation $P$ could result in a much larger effect on annual $Q$ in nonhumid regions (Milly and Dunne 2002; Roderick and Farquhar 2011), thus leading to a more biased estimation of $Q$ there. In addition, the accuracy of annual $Q$ predictability is restricted by ecological signatures (Donohue et al. 2010; Liang et al. 2015), climate change (Liang et al. 2015; Renner and Bernhofer 2012), and human interferences (Patterson et al. 2013; Wang and Hejazi 2011) in both humid and nonhumid regions.

The uncertainties of estimated and predicted ET and $Q$ are major concerns of hydrologic science (Kumar 2011; Sivapalan et al. 2003). In general, the predictability problems are related to their fluctuations or instabilities (Kumar 2011; Vogel et al. 2015). To improve the capacity of predicting annual ET and $Q$, a better knowledge of their variability is of special importance under a changing climate and substantial anthropogenic interference (Kumar 2011; Kumar et al. 2016; Vano et al. 2008). Recently, considerable efforts have been devoted to diagnosing the interannual variability of ET and $Q$ with respect to $P$ (Peel et al. 2004), $\Delta S$ (Wang et al. 2009), vegetation (Donohue et al. 2010), catchment properties (Maurer et al. 2004; Vano et al. 2008), and the combined effect of these factors (Cheng et al. 2011). Most of the variability of annual $P$ was transferred to $Q$ variability under humid conditions, but in nonhumid conditions, most of the variability of annual $P$ was transferred to the variability of $\Delta S$ (Wang and Alimohammadi 2012). Detailed analysis showed that $\Delta S$ could further dampen/enhance ET variability at annual time scales (Zeng and Cai 2016). The ET variability could be overestimated by assuming a negligible annual $\Delta S$, particularly in nonhumid catchments (Wang and Alimohammadi 2012).

However, the inconformity can also exist in the analysis of both annual ET and $Q$ variability between humid and nonhumid regions. One study found that the interannual variability of ET is affected strongly by $P$ (Ukkola and Prentice 2013) in both humid and nonhumid catchments, while another study concluded that this variability is controlled by both $P$ and potential evaporation (PET; Zeng and Cai 2016). In addition, the strong effect of the variability of $P$ on annual $Q$ variability was evident in both humid and nonhumid regions (Peel et al. 2001; Vano et al. 2008). However, Milly and Dunne (2002) showed that the influence of variability of $P$ on annual $Q$ variability was 


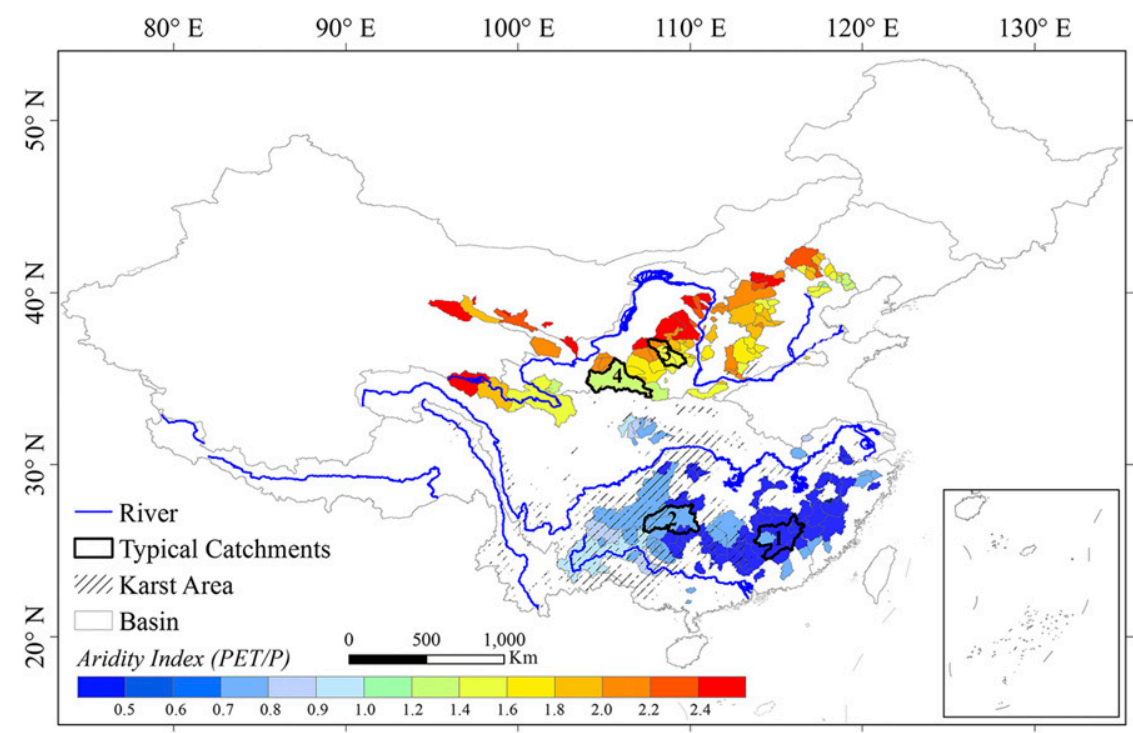

FIG. 1. The spatial distribution of catchments in humid $(\mathrm{PET} / P<1)$ and nonhumid $(\mathrm{PET} / P>1)$ areas categorized by the aridity index. The four selected typical catchments are labeled from 1 to 4 with catchments 1 and 2 being humid catchments (the first in a nonkarst area and the second in a karst region), and catchments 3 and 4 are the two nonhumid catchments. These were chosen for their long-term data series and large catchment areas.

minor in humid regions while significant in nonhumid regions. Nevertheless, systematic analyses of the variability and predictability of annual ET and $Q$, and elucidating why and how they vary in humid (aridity index $\bar{\phi} \mathrm{PET} / P<1$ ) and nonhumid catchments $(\bar{\phi}>1)$, are rare.

In this study, we attempt to address three scientific questions:

1) Do different patterns exist in ET and $Q$ predictability between humid and nonhumid catchments at annual time scales?

2) How different is the variability of interannual ET and $Q$ between humid and nonhumid catchments since it is related to their predictability?

3) What causes the difference in predictability of annual ET and $Q$ between humid and nonhumid catchments?

To answer these questions, we analyze the spatially distributed annual $Q$ dataset derived from observations and ET based on Fu's (1981) equation, using data from 102 humid catchments and 108 nonhumid catchments over China. We present the differences of the predictability of annual ET and $Q$ between humid and nonhumid catchments in sections $3 \mathrm{a}$ and $3 \mathrm{~b}$. We explore the differences of their variability in section $3 c$ and the effect of $\Delta S$ in section $3 \mathrm{~d}$ to seek for plausible explanations for this difference. We close with a brief summary and conclusions.

\section{Data and methods}

\section{a. The humid and nonhumid catchments in China}

We collect the datasets in 210 catchments spatially distributed from arid to humid conditions, including 108 nonhumid catchments (obtained from Sun 2007) and 102 humid catchments in China (Fig. 1). The 102 humid catchments are located in the Pearl River basin, the southeastern rivers basin, and the middle and lower parts of the Yangtze River basin. Each catchment area ranges from $\sim 600$ to $\sim 126900 \mathrm{~km}^{2}$ with an aridity index smaller than 1.0. Among them, the 42 catchments located in southwest China are nonclosure catchments (each constitutes $>10 \%$ of karst area). The 108 nonhumid catchments are located in the Yellow River basin, the Hai River basin, and the inland river basins with catchment areas ranging from $\sim 270$ to $\sim 98400 \mathrm{~km}^{2}$.

We selected four typical catchments with long-term data series and large catchment areas for current analysis (Fig. 1). The first one is a humid catchment in a nonkarst area [hereafter humid (normal)] with the hydrological station Dongbei and a catchment area of $39625 \mathrm{~km}^{2}$. The second is a humid catchment in a karst area [hereafter humid (karst)] with the hydrological station Anjiang and a catchment area of $40305 \mathrm{~km}^{2}$. The third and the forth are two catchments in nonhumid regions (hereafter nonhumid) with the hydrological stations Jiaokouhe and Weijiabao and catchment areas of 17180 and $37006 \mathrm{~km}^{2}$, respectively. 


\section{b. Observed meteorological dataset and runoff}

We obtain the observed runoff $Q_{\text {obs }}$ dataset from the Hydrological Bureau of China. While the earliest data could be traced back to 1950 , most of the recorded runoff data were concentrated in 1960-2013 for both humid and nonhumid catchments. The observed $P$ and other meteorological forcing (surface air temperature, sunshine duration, relative humidity, and wind speed) for the PET calculation were obtained from the daily ground climatological dataset from the China Meteorological Data Network (http://data.cma.cn/) for 19512013 , containing a maximum of up to 756 sites. The accumulated monthly $P$ and PET were interpolated [using the inverse distance weighting (IDW) method] and extracted at catchment scale to form the annual time series corresponding to those $Q_{\text {obs }}$.

We used the data from before the year 2000 for calibration, and more importantly, evaluation of the predictability of annual ET and $Q$ in humid and nonhumid catchments, respectively. The dataset after 2000 was adopted to validate the difference of predictability skill in annual ET and $Q$ between humid and nonhumid catchments.

\section{c. The Budyko framework}

Based on the findings of Schreiber (1904) and Ol'Dekop (1911), Budyko $(1963,1974)$ derived the wellknown "Budyko curve," which describes the waterenergy balance status of a catchment. Fu (1981) extended that original work to the form of differential equations, enabling the derivation of analytical solutions. It describes the competition between available water (humid catchments, represented by $P$ ) and available energy (nonhumid catchments, represented by PET $)$ in terms of the aridity index $(\bar{\phi}=\mathrm{PET} / P)$. The Fu's type of Budyko equation has been used in various research in long-term annual water-energy balances in both nonhumid (Yang et al. 2007; Sun 2007) and humid catchments (Tekleab et al. 2011; Xu et al. 2013) and is as follows:

$\frac{\mathrm{ET}}{P}=f\left(\frac{\mathrm{PET}}{P}\right)=1+\frac{\mathrm{PET}}{P}-\left[1+\left(\frac{\mathrm{PET}}{P}\right)^{w}\right]^{1 / w}$,

where $w$ is a dimensionless parameter related to the catchment condition. We estimate the PET using the FAO Penman equation (Allen et al. 1998):

$\mathrm{PET}=\frac{0.408 \Delta\left(R_{n}-G\right)+\gamma \frac{900}{T+273} u_{2} e_{s}(1-\mathrm{Rh} / 100)}{\Delta+\gamma\left(1+0.34 u_{2}\right)}$, where $R_{n}$ is the net radiation $\left(\mathrm{MJ} \mathrm{m}^{-2} \mathrm{day}^{-1}\right), \Delta$ is the slope of the vapor pressure curve $\left(\mathrm{kPa}^{\circ} \mathrm{C}^{-1}\right), G$ is the soil heat flux $\left(\mathrm{MJ} \mathrm{m}^{-2} \mathrm{day}^{-1}\right), u_{2}$ is the wind speed at 2-m height $\left(\mathrm{m} \mathrm{s}^{-1}\right), \gamma$ is the psychometric constant $\left(\mathrm{kPa}{ }^{\circ} \mathrm{C}^{-1}\right), e_{s}(\mathrm{kPa})$ is the saturation vapor pressure at a given air temperature, and $\mathrm{Rh}$ is the relative humidity.

To further analyze the differences of annual ET and $Q$ variability between humid and nonhumid catchments, a variance decomposition framework based on the Fu's type of Budyko equation was adopted and used to derive interannual ET variability from the variability of $P$ and PET (Zeng and Cai 2015). Here, we assume that the annual $\Delta S$ is approximately zero in the water balance equation, as is the common practice, and derive the interannual variability of ET and $Q$ using this variance decomposition framework. Detailed decompositions of their variability into variance/covariance of $P$ and PET are as follows:

$\sigma_{\mathrm{ET}}^{2}=a_{\mathrm{ET}}^{2} \sigma_{P}^{2}+b_{\mathrm{ET}}^{2} \sigma_{\mathrm{PET}}^{2}+2 a_{\mathrm{ET}} b_{\mathrm{ET}} \operatorname{cov}(P, \mathrm{PET})$

and

$$
\sigma_{Q}^{2}=a_{Q}^{2} \sigma_{P}^{2}+b_{Q}^{2} \sigma_{\mathrm{PET}}^{2}-2 a_{Q} b_{Q} \operatorname{cov}(P, \mathrm{PET}),
$$

where $\sigma$ is the standard deviation and cov represents the covariance. The parameters $a$ and $b$ are the weighting factors quantifying the contribution of $P$ and PET to the variability of annual ET and $Q$, respectively. The analytical calculations are as follows:

$$
\begin{aligned}
a_{\mathrm{ET}} & =f(\bar{\phi})-f^{\prime}(\bar{\phi}) \bar{\phi}, \\
b_{\mathrm{ET}} & =f^{\prime}(\bar{\phi}), \\
a_{Q} & =1-f(\bar{\phi})+f^{\prime}(\bar{\phi}) \bar{\phi}, \quad \text { and } \\
b_{Q} & =f^{\prime}(\bar{\phi}),
\end{aligned}
$$

where $\bar{P}$ and $\overline{\mathrm{PET}}$ are the multiannual mean of $P$ and PET in each catchment, and $\bar{\phi}=\overline{P / P E T}$.

\section{Results}

\section{a. The calibration of parameter $w$ in the Budyko framework}

We first present the relationship between the aridity index $(\mathrm{PET} / P)$ and the evaporative index $(\mathrm{ET} / P)$ for 102 humid (42 in the karst area and 60 in the nonkarst region, i.e., normal region) and 108 nonhumid catchments in Fig. 2a. Consistent with the Budyko hypothesis, we find that humid and nonhumid catchments demonstrate the characteristics of energy-limited and water-limited conditions, respectively (Carmona et al. 2016; Fu 1981; Ukkola and Prentice 2013; Zhang et al. 2001, 2004). 

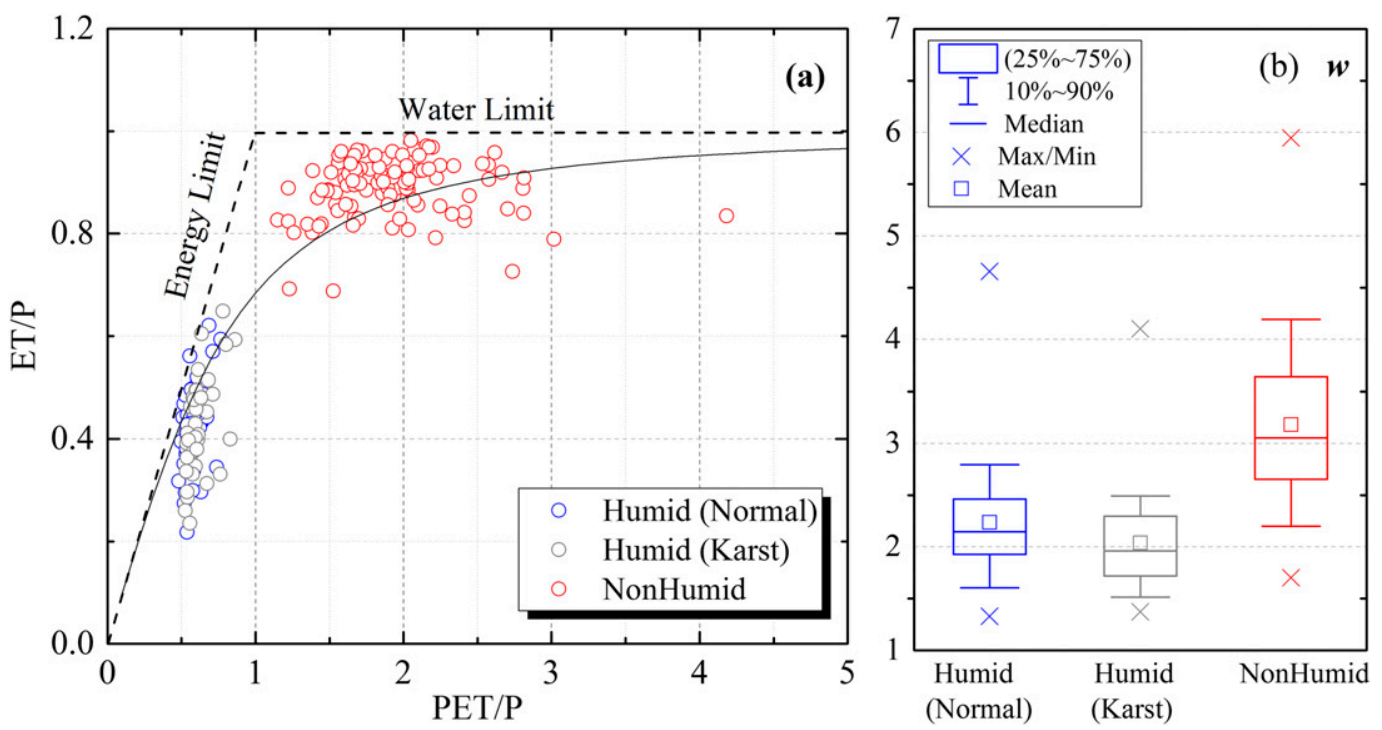

FIG. 2. (a) Fu's type of Budyko curve in humid and nonhumid catchments over China, and (b) a box plot of parameter $w$ in humid [catchments in the karst region (karst) and in nonkarst areas (normal)] and nonhumid catchments, respectively.

We then calibrate the parameter $w$ in Fu's type of Budyko equation [i.e., Eq. (1)]. To do this, we use $P$, PET, and ET (i.e., $P-Q_{\text {obs }}$ ) from before the year 2000 to form the annual time series of $\mathrm{PET} / P$ as independent variables and $\mathrm{ET} / P$ as dependent variables for each catchment, and the parameter $w$ is the remaining unknown variable in Eq. (1). We find that the calibrated parameter $w$ varies greatly between humid and nonhumid catchments, but does not vary much among normal humid catchments and those in the karst region (Fig. 2b). For humid catchments, the mean $w$ values for the normal and karst regions are 2.23 (10th percentile, 1.54; 90th percentile, 2.74) and 2.03 (10th percentile, 1.49; 90th percentile, 2.42), respectively. By contrast, for nonhumid catchments, the mean $w$ is 3.18 (10th percentile, 2.16; 90th percentile, 4.18). In a sense, the parameter $w$ generalizes the catchment characteristics, for example, the vegetation cover and water-energy conditions.

\section{b. The difference of predictability of annual ET and $Q$ between humid and nonhumid catchments}

Using the calibrated parameter $w$, we first present the differences of predictability of annual ET and $Q$ between humid and nonhumid catchments based on data ( $P$, PET, $\left.Q_{\text {obs }}\right)$ before the year 2000 . We estimate the annual time series of ET using Fu's type of Budyko equation (denoted $\mathrm{ET}_{\text {Budyko }}$ ) and compare it with $\mathrm{ET}$ from the water balance equation $\left(\mathrm{ET}_{\mathrm{wb}}\right.$; i.e., $\mathrm{ET}_{\mathrm{wb}}=$ $P-Q_{\text {obs }}-\Delta S$, where annual $\Delta S \sim 0$ ). The simulated runoff $Q_{\text {sim }}$ (i.e., $Q_{\text {sim }}=P-\mathrm{ET}_{\text {Budyko }}-\Delta S$, where annual $\Delta S \sim 0$ ) was validated against $Q_{\text {obs }}$ at an annual time scale.
Comparison of $R^{2}$ for $\mathrm{ET}_{\mathrm{wb}}$ and $\mathrm{ET}_{\text {Budyko }}$ between 102 humid catchments (60 in the normal region and 42 catchments in the karst region) and 108 nonhumid catchments are shown in Figs. 3a-3c and that for $Q_{\text {obs }}$ and $Q_{\text {sim }}$ are shown in Figs. 3d-3f, respectively. Less reliable predictability of annual ET is detected, with $R^{2}$ lower than 0.2 in most humid catchments (both in the normal and karst regions; Figs. 3a,b), while annual ET is predictable in nonhumid regions, with $R^{2}$ almost all higher than 0.7 (Fig. 3c). Thus, annual ET is predictable in nonhumid regions but is less predictable in humid regions. Similarly, annual $Q$ is predictable in humid regions with $R^{2}$ greater than 0.6 in most humid catchments but is less predictable in nonhumid regions with $R^{2}$ smaller than 0.5 in about two-thirds of the catchments. These are in line with the findings based on other approaches, for example, remote sensing (Cheng et al. 2011; Zhang et al. 2012) and hydrological models (Sankarasubramanian and Vogel 2002).

To present detailed information about the difference of predictability of ET and $Q$ between humid and nonhumid regions, we plot the variations of the annual time series of ET and $Q$ for four selected catchments. The fluctuations of annual $\mathrm{ET}_{\mathrm{wb}}$ are poorly captured by $\mathrm{ET}_{\text {Budyko }}$ in the humid and karst regions (Figs. 4a,b), with $R^{2}$ of 0.05 and 0.15 , and with the ratios [the root-mean-square error (RMSE) between $\mathrm{ET}_{\mathrm{wb}}$ and $\mathrm{ET}_{\text {Budyko against the corre- }}$ sponding multiannual $\mathrm{ET}_{\mathrm{wb}}$ ] reaching $\sim 28.6 \%$ and $\sim 13.0 \%$, respectively. In contrast, $\mathrm{ET}_{\text {Budyko }}$ reliably simulates the annual $\mathrm{ET}_{\mathrm{wb}}$ in nonhumid catchments (Figs. 4c,d), with high $R^{2}$ of 0.96 and 0.86 , and the abovementioned ratios of less than $4.6 \%$ and $6.9 \%$. 


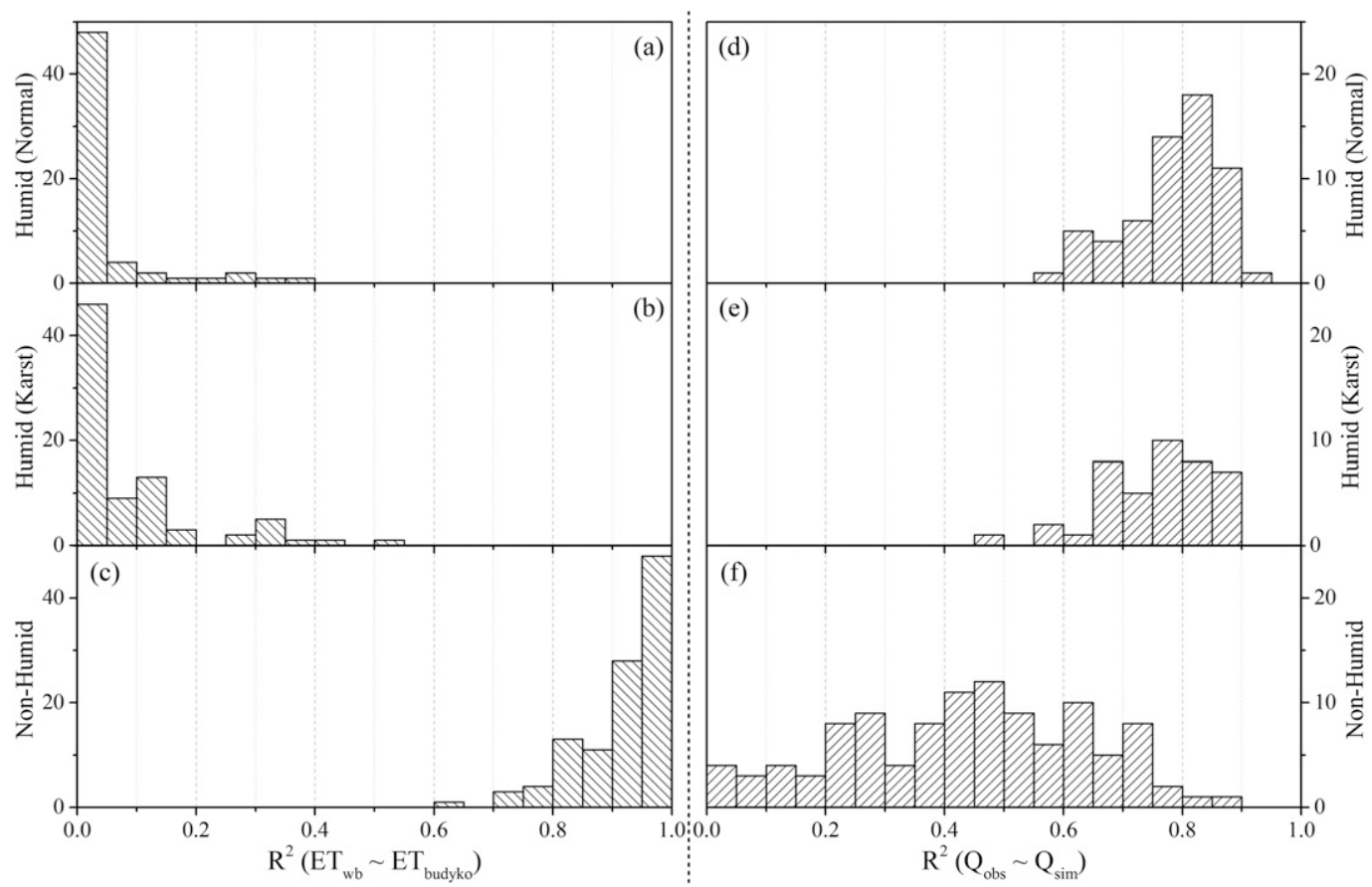

FIG. 3. The statistical histograms of $R^{2}$ between annual $\mathrm{ET}_{\text {Budyko }}$ and $\mathrm{ET}_{\mathrm{wb}}$, and $Q_{\mathrm{obs}}$ and $Q_{\text {sim }}$ $\left(Q_{\text {sim }}=P-\mathrm{ET}_{\text {Budyko }}-\Delta S\right.$, where $\left.\Delta S \sim 0\right)$, in (a),(d) 60 normal humid catchments; (b),(e) 42 humid catchments in the karst region; and (c),(f) 108 nonhumid catchments. The data ( $P$, PET, and $\left.Q_{\text {obs }}\right)$ used are from before the year 2000.

These show a clear advantage of Fu's type of Budyko equation [i.e., Eq. (1)] in annual ET estimation, and hence, predictability in nonhumid catchments compared to that in humid catchments.

Prediction of annual $Q$ in humid catchments has been satisfactory (Figs. 4e,f). In the two nonhumid catchments (Figs. $4 \mathrm{~g}, \mathrm{~h}$ ), the $R^{2}$ are 0.51 and 0.49 , and the ratios (i.e., RMSE of $Q_{\text {obs }}$ and $Q_{\text {sim }}$ against corresponding multiannual $Q_{\text {obs }}$ ) are $90.9 \%$ and $46.9 \%$, respectively. In contrast, in the normal humid and karst regions, the $R^{2}$ values are high enough to hit 0.87 and 0.66 , and these ratios are less than $10.6 \%$ and $12.8 \%$, respectively. Hence, successful prediction of annual $Q$ is achievable in humid catchments rather than in nonhumid catchments.

From the calibrated $w$ (see section 3a), we perform model validation using post-2000 data over China (consisting of 54 humid catchments and 63 nonhumid catchments with data for at least 7 years in each catchment). The model has good predictability for annual ET in nonhumid catchments $\left[R^{2}\left(\mathrm{ET}_{\mathrm{wb}}\right.\right.$ versus $\left.\mathrm{ET}_{\text {Budyko }}\right)$ in the 25th percentile is 0.94 and in the 90th percentile is $\sim 1.0]$ and annual $Q$ in humid catchments $\left[R^{2}\left(Q_{\text {obs }}\right.\right.$ versus $\left.Q_{\text {sim }}\right)$ in the 25th percentile is 0.70 and in the 75 th percentile is 0.89 ]. However, its predictability is relatively poor for annual ET in humid catchments $\left(R^{2}\right.$ in the 25th percentile is 0.06 and in the 75th percentile is 0.38 ) and annual $Q$ in nonhumid catchments $\left(R^{2}\right.$ in the 25 th percentile is
0.06 and in the 75th percentile is 0.50) (Fig. 5). These outcomes further confirm our earlier conclusion.

Above all, we confirmed that annual ET is predictable in nonhumid regions but is less predictable in humid regions and that annual $Q$ is predictable in humid regions but less reliable in nonhumid regions.

\section{c. The effect of variability on the predictability of annual ET and $Q$}

To advance our ability in predicting annual ET and $Q$ in both humid and nonhumid catchments, a better knowledge of their variability in different regions is one key aspect to understanding the uncertainty of the prediction. We took three categories of catchments: 60 normal humid catchments, 42 in the karst region, and 108 nonhumid catchments and adopted a variance decomposition framework based on the Budyko framework [Eqs. (3)-(5)]. The comparisons of variability of annual ET [the sum of contribution of each component $\operatorname{Var}(\mathrm{ET})$ against the variability of $\mathrm{ET}_{\text {Budyko }}$ $\left.\operatorname{Var}\left(\mathrm{ET}_{\text {Budyko }}\right)\right]$ and $Q\left[\operatorname{Var}(Q)\right.$ against $\left.\operatorname{Var}\left(Q_{\text {obs }}\right)\right]$ in three categories of catchments are shown in Fig. 6. Strong correlation has been found between $\operatorname{Var}\left(\mathrm{ET}_{\text {Budyko }}\right)$ and $\operatorname{Var}(\mathrm{ET})$ with high $R^{2}$ of 0.96 and 0.97 in normal and karst humid catchments (Fig. 6a) and 0.98 in nonhumid catchments (Fig. 6b). Weaker but acceptable correlations have been achieved between 

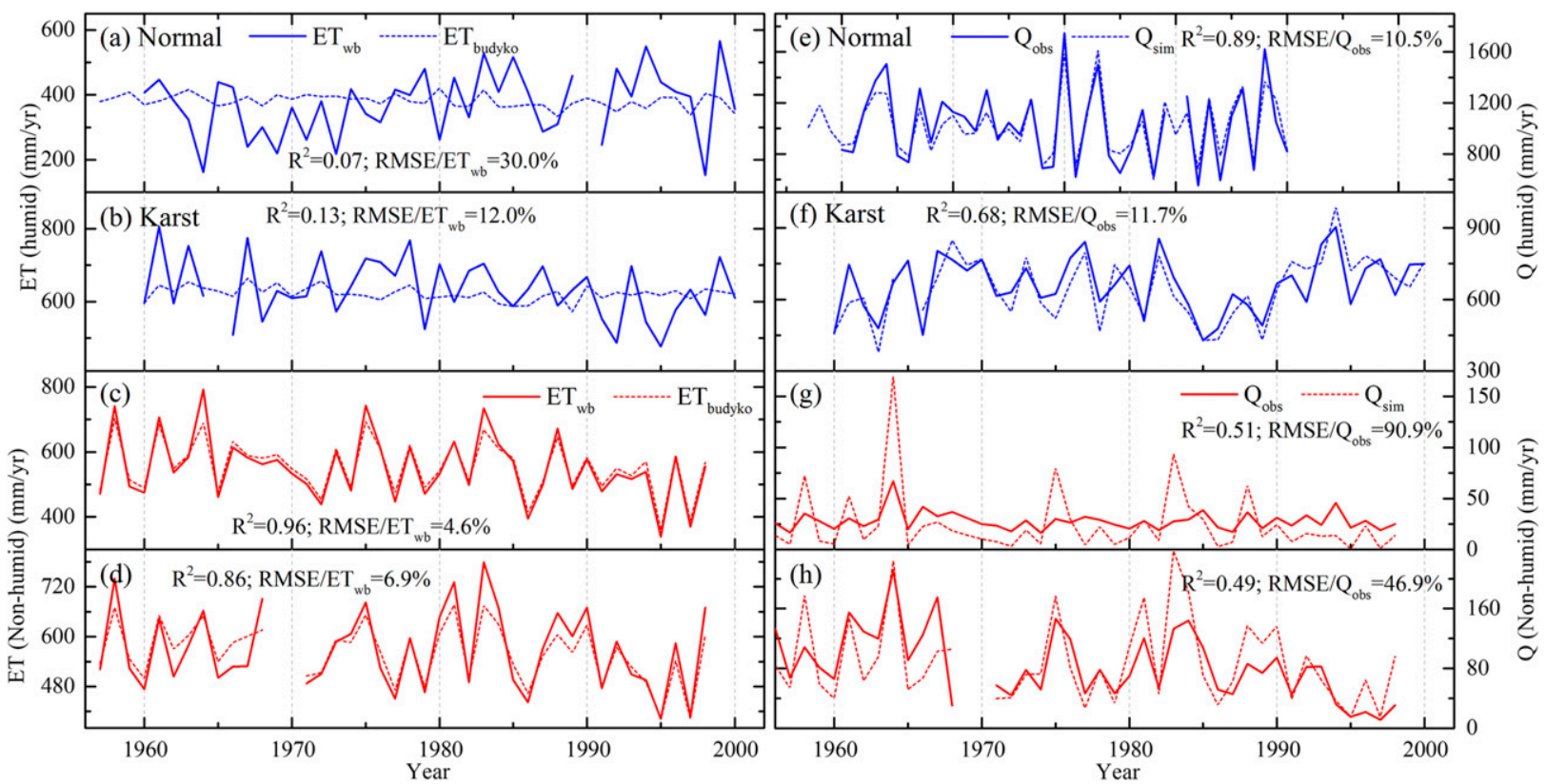

FIG. 4. The time series of annual $\mathrm{ET}_{\text {Budyko }}$ (estimated based on the Budyko equation) and $\mathrm{ET}_{\mathrm{wb}}$ (calculated using the water balance equation), as well as observed and simulated annual $Q$ in four selected catchments (distribution in Fig. 1): (a),(e) in normal humid catchments, (b),(f) in the karst region, and (c),(d),(g),(h) in two nonhumid catchments.

$\operatorname{Var}(Q)$ and $\operatorname{Var}\left(Q_{\text {obs }}\right)$ in both humid (Fig. 6c) and nonhumid catchments (Fig. 6d). Therefore, this method can be used in analyzing the contribution of the variability of $P$, PET, and their covariance to the variability of annual ET and $Q$, respectively, for both nonhumid catchments and humid catchments in normal and karst regions.

Differences exist in the relative contribution to annual ET variability between humid and nonhumid catchments. In nonhumid catchments, the annual ET variability averaged approximately $5600 \mathrm{~mm}^{2} \mathrm{yr}^{-2}$ with a range from 760 to $20500 \mathrm{~mm}^{2} \mathrm{yr}^{-2}$ (see Figs. S1a,d in the online supplemental material). The variability of $P$ has a dominant role, which accounts for an average of approximately $93.9 \%$ with a range of $81.1 \%-99.7 \%$ of the total contribution to the variability of annual ET (Fig. 7a). This is mainly because the ET is limited by available water in nonhumid catchments. (Fu 1981); with greater variability of $P$ (Fig. S2) comes greater variability of ET. For example, the relatively smaller $P$ and its variability in several inland
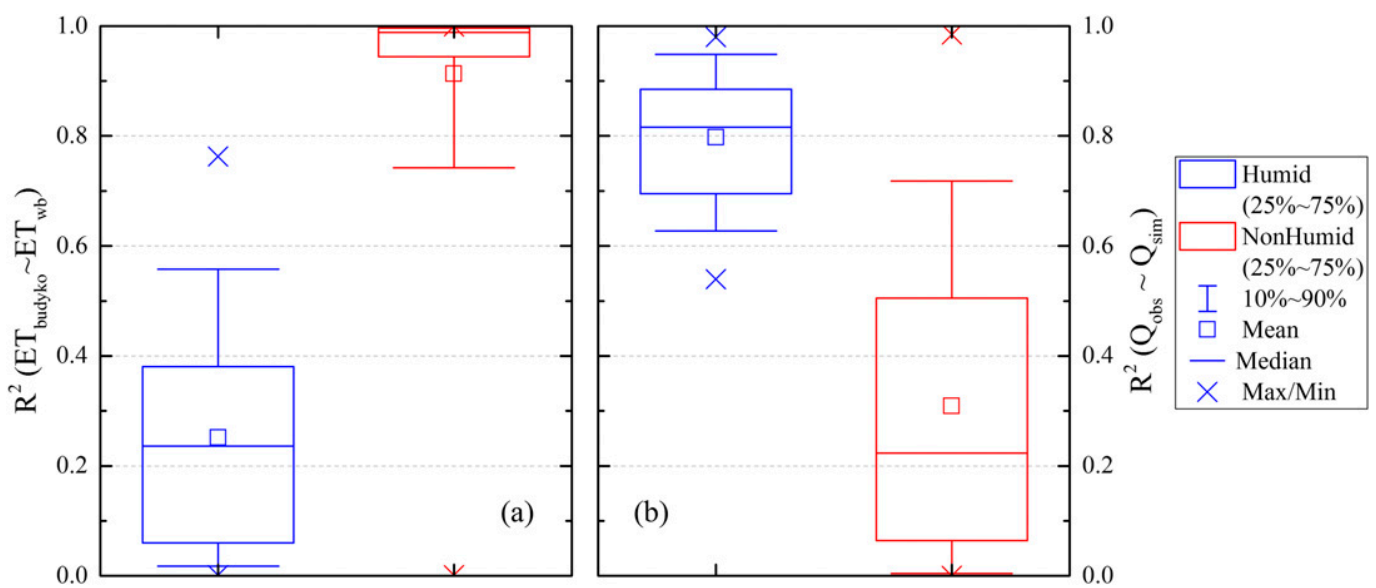

FIG. 5. The box plot of $R^{2}$ in predicting annual (a) ET $\left(\mathrm{ET}_{\text {Budyko }} \mathrm{vs}_{\mathrm{ET}}\right)$ and (b) $Q\left(Q_{\mathrm{obs}} \mathrm{vs} Q_{\text {sim }}\right)$ for humid (blue boxes, 54 catchments) and nonhumid (red boxes, 63 catchments) regions using data ( $P$, PET, and $\left.Q_{\text {obs }}\right)$ post-2000 and parameter $w$ calibrated based on data before 2000 in Fu's type of Budyko equation. 

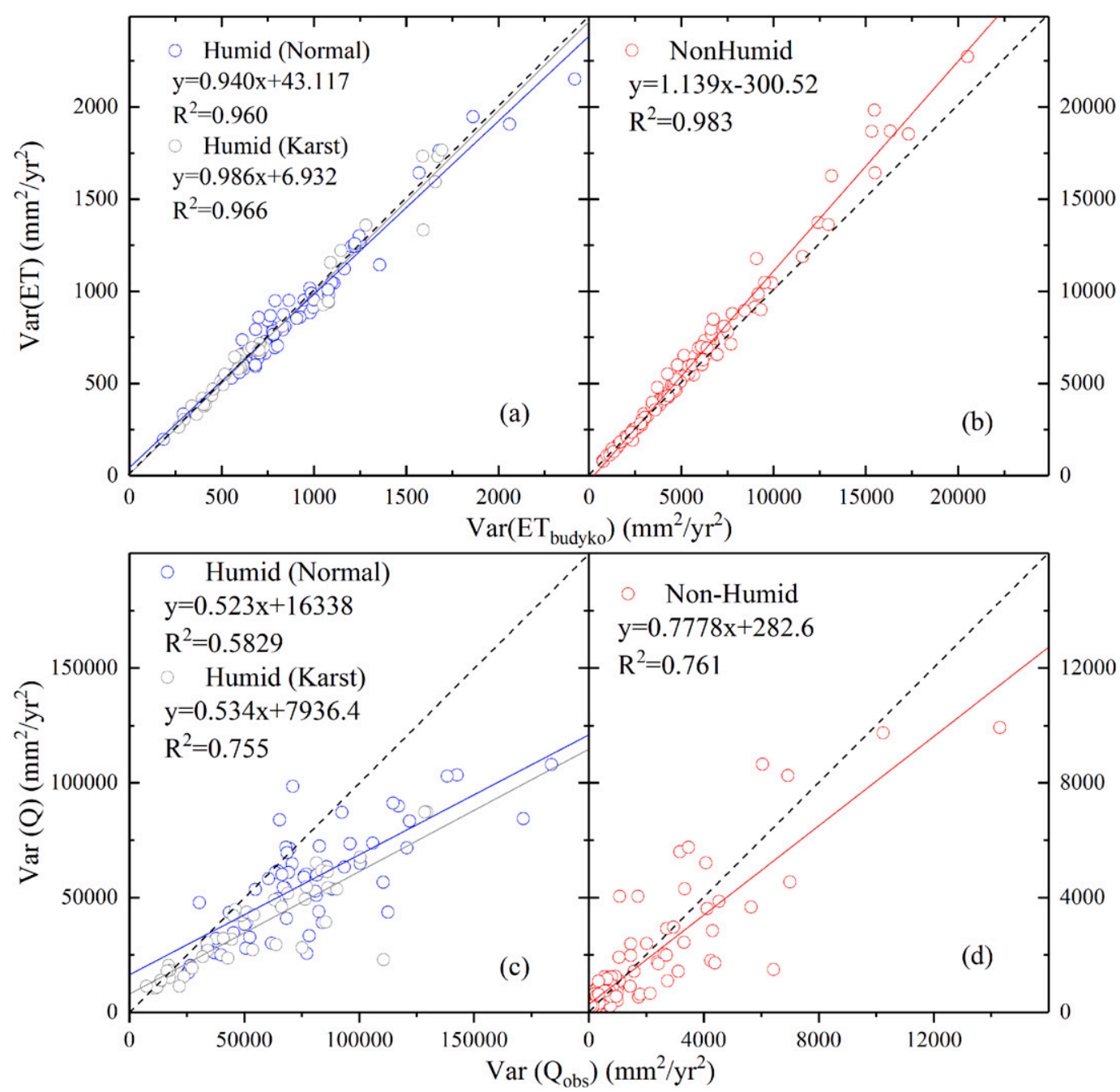

FIG. 6. The comparison of variability of $\mathrm{ET}_{\text {Budyko }}\left[\operatorname{Var}\left(\mathrm{ET}_{\text {Budyko }}\right)\right]$ against that calculated based on the contribution of $P$, PET, and their covariance $[\operatorname{Var}(\mathrm{ET})]$ in (a) humid catchments (normal and karst regions) and (b) nonhumid catchments. (c),(d) As in (a),(b), but for the variability of observed and simulated $Q$.

catchments (northwest China) led to less ET variability when compared to some other nonhumid catchments (north and northeast parts of China; Fig. S1a). In humid catchments, the variability of ET is smaller (averaging approximately 900 and $760 \mathrm{~mm}^{2} \mathrm{yr}^{-2}$ in 60 normal regions and 42 karst areas with ranges of 200 2400 and $270-1700 \mathrm{~mm}^{2} \mathrm{yr}^{-2}$, respectively; Fig. S1c). The variability of $P$, PET, and their covariance takes considerable proportions (averaged approximately $38.4 \%, 28.4 \%$, and $33.2 \%$ in normal humid regions and $44.9 \%, 25.7 \%$, and $29.4 \%$ in karst regions, respectively) to the variability of annual ET. Hence, the dominant control of variability of $P$ on annual ET variability is one possible explanation for its good predictability in nonhumid catchments. While in humid catchments, the relatively complicated controlling factors make it difficult to form annual ET predictions. This can partly explain the difference of annual ET predictability between humid and nonhumid catchments.

The relative contributions of $P$, PET, and their covariance to annual $Q$ variability are simple. The variability of $P$ has the dominant control, which averaged approximately $83.4 \%$ with a range of $70.0 \%-99.1 \%$ in nonhumid catchments, and $87.3 \%$ and $87.7 \%$ with a range of $77.0 \%-94.2 \%$ and $81.6 \%-96.3 \%$ for normal humid catchments and for the karst region, respectively (Fig. 7b). Therefore, the larger the $P$ is, the larger its variability and thus the variability of annual $Q$. The averaged $Q$ variability in nonhumid catchments is only approximately $1500 \mathrm{~mm}^{2} \mathrm{yr}^{-2}$ with a range of $\sim 10-14000 \mathrm{~mm}^{2} \mathrm{yr}^{-2}$, while it reaches up to $\sim 77000$ and 


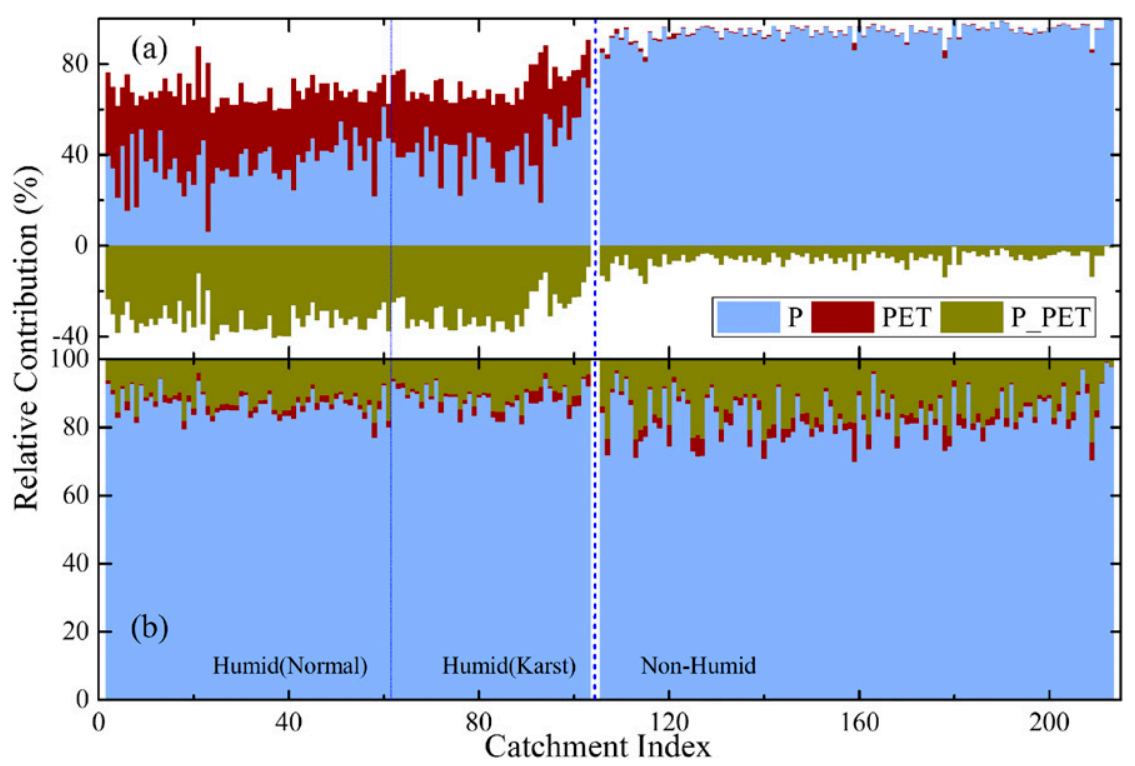

FIG. 7. The relative contribution of $P, \mathrm{PET}$, and their covariance ( $P \_$PET) to the variability of annual (a) ET and (b) $Q$ in both humid (normal and karst) and nonhumid catchments ascending by the aridity index $(\mathrm{PET} / P)$.

$53000 \mathrm{~mm}^{2} \mathrm{yr}^{-2}$ with ranges of $\sim 26000-184000 \mathrm{~mm}^{2} \mathrm{yr}^{-2}$ and $\sim 7500-130000 \mathrm{~mm}^{2} \mathrm{yr}^{-2}$ in normal humid catchments and in karst regions, respectively (Figs. S1b,e,f). Hence, this simple comparison of the variability of annual $Q$ cannot reflect the differences of its predictability between humid and nonhumid catchments.

Above all, the differences in the controlling factors on the variability of annual ET can be, to some extent, one possible explanation for the differences of predictability between humid and nonhumid catchments. However, the variability analysis fails to explain their differences in annual $Q$. Further analysis is needed to explicate the difference of predictability of annual $Q$ and to better understand the predictability of annual ET in humid and nonhumid catchments.

\section{d. The effect of $\Delta S$ on the predictability of annual ET and $Q$}

\section{1) THE EFFECT OF $\Delta S$ ON THE ESTIMATION OF ET AND $Q$}

Comparisons above (see sections $3 \mathrm{~b}$ and $3 \mathrm{c}$ ) were based on the assumption that the annual $\Delta S \sim 0$ in the water balance equation. However, the averaged runoff coefficient $\left(\overline{Q_{\mathrm{obs}}} / \bar{P}\right)$ for the 108 nonhumid catchments is $\sim 0.11$, which means $\sim 90 \%$ of $P$ turns into ET and $\sim 10 \%$ of $P$ turns into $Q$ in these nonhumid catchments. In this sense, $Q$ is highly sensitive to the variation of $\Delta S$. In humid regions, the averaged runoff coefficient for the 102 humid catchments is $\sim 0.57$. This means that $\sim 57 \%$ and $\sim 43 \%$ of $P$ turn into
$Q$ and ET, respectively. Thus, $Q$ (ET) is somewhat less (more) sensitive to $\Delta S$ than that of the former case. Hence, neglecting annual $\Delta S$ would affect the estimation of ET and $Q$ for humid and nonhumid catchments.

To present the difference in proportion of partitioning of $P$ into $Q$ and ET between humid and nonhumid regions, we assume that the $\mathrm{ET}_{\text {Budyko }}$ is acceptable to estimate ET. We calculate annual $\Delta S$ at the catchment scale using the water balance equation (i.e., $P-Q_{\mathrm{obs}}-\mathrm{ET}_{\text {Budyko }}$ ) in that there is no observed $\Delta S$ available, and inaccuracy and uncertainty exists in the estimates in modeled $\Delta S$ in many existing hydrological models. The averages of annual $\Delta S / \mathrm{ET}_{\text {Budyko }}$ and $\Delta S / Q_{\text {obs }}$ in each catchment (Figs. 8a,b) show that annual $\Delta S$ can affect the estimation and prediction of annual ET and $Q$ in humid and nonhumid catchments at different levels. The $\Delta S / \mathrm{ET}_{\text {Budyko }}$ is quite small in nonhumid regions with an average of $4.67 \%$ for 108 catchments. It accounts for a relatively large proportion in humid regions, with averages of $15.16 \%$ in 102 catchments (averages of $15.38 \%$ for 60 normal humid catchments and $14.83 \%$ for 42 catchments in karst regions). This demonstrates that neglecting annual $\Delta S$ can affect ET estimation and prediction more in humid regions. The opposite is true for $\Delta S / Q_{\text {obs }}$, which averages $69.32 \%$ in nonhumid catchments but only $17.16 \%$ in humid catchments. This shows that neglecting annual $\Delta S$ would affect annual $Q$ estimation more and reduce its predictability in nonhumid catchments. 

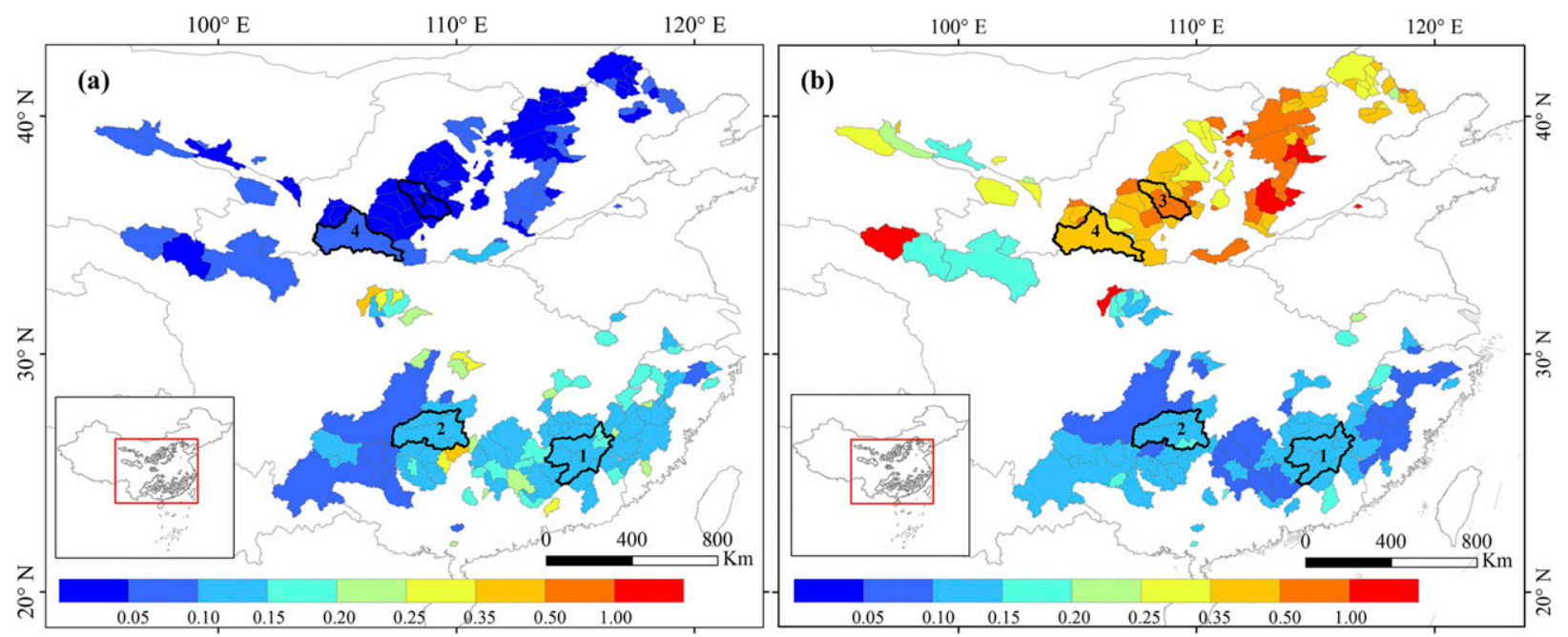

FIG. 8. The ratios of annual (a) $\Delta S / \mathrm{ET}_{\text {Budyko }}$ and (b) $\Delta S / Q_{\text {obs }}$ in both humid and nonhumid catchments over China. The $\Delta S$ is obtained from $P-Q_{\text {obs }}-\mathrm{ET}_{\text {Budyko }}$.

\section{2) THE EFFECT OF $\Delta S$ ON THE VARIABILITY OF ET AND $Q$}

In addition, it is possible that neglecting annual $\Delta S$ affects the variability of ET in humid catchments and $Q$ in nonhumid catchments significantly, and thus results in the differences in their predictability in humid and nonhumid catchments. Here we attempt to find out the differences of neglecting annual $\Delta S$ to the variability of annual ET and $Q$ between humid and nonhumid catchments. Two ratios $n_{1}$ and $n_{2}$ are defined as

$$
\begin{aligned}
& n_{1}=\frac{\sigma^{2}\left(\mathrm{ET}_{\mathrm{wb}}\right)}{\sigma^{2}\left(\mathrm{ET}_{\text {Budyko }}\right)}=\frac{\sigma^{2}\left(P-Q_{\text {obs }}\right)}{\sigma^{2}\left(P-Q_{\text {obs }}-\Delta S\right)} \quad \text { and } \\
& n_{2}=\frac{\sigma^{2}\left(Q_{\text {sim }}\right)}{\sigma^{2}\left(Q_{\text {obs }}\right)}=\frac{\sigma^{2}\left(P-\mathrm{ET}_{\text {Budyko }}\right)}{\sigma^{2}\left(P-\mathrm{ET}_{\text {Budyko }}-\Delta S\right)}
\end{aligned}
$$

When $\Delta S$ is small enough, $n_{1}$ and $n_{2}$ approach 1.0 $\left(n_{1} \rightarrow 1.0\right.$ and $\left.n_{2} \rightarrow 1.0\right)$, which means the effect of annual $\Delta S$ on the variability of ET and $Q$ diminishes. The two ratios, to some extent, can indicate the differences of the effect of neglecting annual $\Delta S$ on the variability of ET and $Q$ between humid and nonhumid catchments, respectively.

We present the results of $n_{1}$ and $n_{2}$ for 60 normal humid catchments, 42 humid catchments in the karst region, and 108 nonhumid catchments in Fig. 9. The annual $\Delta S$ affects the ET variability in nonhumid regions much less with $n_{1}$ approaching 1.0 (average of 1.63 and 10th percentile, 1.17; 90th percentile, 2.11), when comparing against that in humid regions (averages of 24.55 and 20.80 , and 10th-90th percentiles of 7.45-34.70 and 5.71-39.35 in normal humid catchments and in the karst region, respectively). The opposite results of
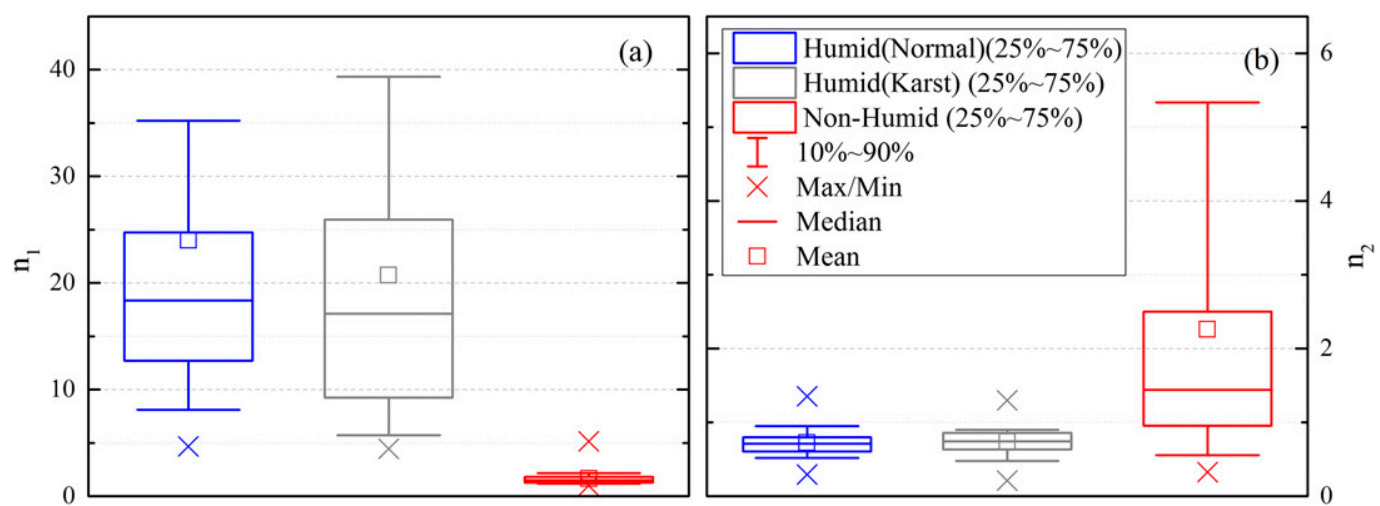

FIG. 9. Box plots of parameters (a) $n_{1}$ (indicating the effect of neglecting annual $\Delta S$ to ET variability) and (b) $n_{2}$ (similar to $n_{1}$, but for $Q$ variability) for both humid and nonhumid catchments. 
neglecting annual $\Delta S$ on $Q$ variability are achieved with $n_{2}$ much smaller in humid regions (averages of 0.72 with 10th-90th percentile of $0.51-0.91$ in 60 normal humid catchments, and 0.74 with 10th-90th percentile of 0.47 0.90 in 42 catchments in the karst region) than those in nonhumid regions (average of 2.26 and 10th-90th percentile of 0.56-5.20). These indicate that the annual $\Delta S$ plays a decisive role in $Q$ variability in nonhumid catchments and in annual ET variability in humid catchments. Additionally, neglecting annual $\Delta S$ can cause a large difference in annual ET and $Q$ predictability between humid and nonhumid catchments.

Above all, neglecting annual $\Delta S$ not only affects the ET and $Q$ estimation, but also affects their variability and thus their predictability in both humid and nonhumid catchments at different levels. In general, it affects the estimation and variability of annual $Q$ in nonhumid catchments more than those in humid catchments, which directly brings about the complexity of predictability of annual $Q$ in nonhumid regions. On the one hand, for the predictability of annual ET, neglecting annual $\Delta S$ can lead to a larger bias in its estimation and variability in humid catchments. On the other hand, the dominant control of $P$ in nonhumid catchments makes it easy to predict annual ET, while in humid catchments, the contribution of $P$, PET, and their covariance take up a considerable proportion of the ET variability, which makes it a little difficult to predict. The larger bias of neglecting annual $\Delta S$ and its complicated controlling factors in humid catchments lead to less trustworthy predictability of ET when compared with that in nonhumid catchments.

\section{Discussion}

The above comparison and analysis can, to some extent, present and explain the differences of annual ET and $Q$ predictability between humid and nonhumid catchments over China. However, we note that the $\Delta S$ obtained from $P-Q_{\text {obs }}-\mathrm{ET}_{\text {Budyko }}$ can result in some bias since we make a simple assumption that the $\mathrm{ET}_{\text {Budyko }}$ is an accurate representation of ET (above). Moreover, the propagation error due to $\Delta S$ in parameter $w$ calibration can lead to a small bias in $\mathrm{ET}_{\text {Budyko }}$ calibration and validation. Besides, the uncertainty of $\mathrm{ET}_{\text {Budyko }}$ itself is attributed to the bias due to neglecting $\Delta S$ in the above analysis, which, together with the uncertainty of the meteorological observations, can lead to some extra bias in the estimation, variability, and thus predictability of annual ET and $Q$ in both humid and nonhumid catchments. In addition, we interpolated the site-based $P$ and PET to the catchment scale, and the elevation differences among the observation sites (Livneh et al. 2014), the interpolation methods (Bárdossy and Pegram 2013), and the spatial distribution of the sites (Cai et al. 2010) can also add some bias to $P$ and PET at the catchment scale. This can thus affect the predictability of annual ET and $Q$ as well. Hence, it is necessary to further verify this explanation and to improve the ability of annual ET and $Q$ predictability in both humid and nonhumid catchments.

\section{Conclusions and summary}

Reliable predictions of annual ET and $Q$ are important in hydrological research. However, systematic analyses of the difference of the predictability of annual ET and $Q$, and elucidating why and how they vary in different regions, are relatively limited. Hence, we adopted 102 humid (PET/P $<1,60$ normal and 42 in the karst region) and 108 nonhumid $(\mathrm{PET} / P>1)$ catchments over China and compared their predictability in humid and nonhumid regions. We made an effort to explore the plausible explanations for their differences.

Using Fu's type of Budyko equation, we first found that annual ET is predictable in nonhumid regions but is less predictable in humid regions, and annual $Q$ is predictable in humid regions but less reliable in nonhumid regions. The possible explanation is the neglect of annual $\Delta S$, which affects the estimation, variability, and predictability of ET and $Q$ in humid and nonhumid catchments, together with the differences in controlling factors on their variability in different regions. To be specific, neglecting annual $\Delta S$ can lead to a much larger bias in the estimation and variability of $Q$ in nonhumid catchments, which brings about the greater complexity of predictability of annual $Q$ in nonhumid catchments than that in humid catchments. Such an effect is just opposite in annual ET predictability between humid and nonhumid catchments. Moreover, the differences of controlling factors in ET variability in different regions add more differences in the predictability as well. The dominant control of $P$ makes it easy to predict annual ET in nonhumid regions; by contrast, in humid regions, $P$, PET, and their covariance take considerable effort to determine annual ET variations, which leads to a less reliable ET predictability in humid catchments.

The above conclusions provide possible explanations for the varied predictability of annual ET and $Q$ between humid and nonhumid catchments. Further analysis can be conducted from this perspective. In addition, one can predict ET in nonhumid catchments and $Q$ in humid catchments reasonably accurately using hydrological models in a warming climate. Additionally, with proper consideration of $\Delta S$, we can improve the prediction of annual ET and $Q$ in both humid and nonhumid catchments. 
Acknowledgments. This research was supported by the National Key Research and Development Program of China (2016YFC0401401 and 2016YFA0602402), the Key Programs of the Chinese Academy of Sciences (ZDRW-ZS-2017-3-1), the CAS Pioneer Hundred Talents Program (Fubao Sun), the Open Research Fund of State Key Laboratory of Desert and Oasis Ecology in Xinjiang Institute of Ecology and Geography, Chinese Academy of Sciences (CAS), the CPSF-CAS Joint Foundation for Excellent Postdoctoral Fellows, the CAS President's International Fellowship Initiative (2017PC0068), and Natural Science Foundation of China (41601035, 41401037, and 41330529). We wish to thank the editor and three reviewers for their invaluable comments and constructive suggestions to improve the quality of the manuscript.

\section{REFERENCES}

Allen, R. G., L. S. Pereira, D. Raes, and M. Smith, 1998: Crop evapotranspiration: Guidelines for computing crop water requirements. FAO Irrigation and Drainage Paper 56, 300 pp., www.fao.org/docrep/X0490E/X0490E00.htm.

Bárdossy, A., and G. Pegram, 2013: Interpolation of precipitation under topographic influence at different time scales. Water Resour. Res., 49, 4545-4565, https://doi.org/10.1002/ wrcr.20307.

Bierkens, M. F. P., 2015: Global hydrology 2015: State, trends, and directions. Water Resour. Res., 51, 4923-4947, https://doi.org/ 10.1002/2015WR017173.

Budyko, M. I., 1963: Evaporation under Natural Conditions. Israel Program for Scientific Translations, $130 \mathrm{pp}$.

_ 1974: Climate and Life. D. H. Miller, Ed., International Geophysics Series, Vol. 18, Academic Press, 508 pp.

Cai, W., T. Cowan, K. Braganza, D. Jones, and J. Risbey, 2010: Comment on "On the recent warming in the Murray-Darling Basin: Land surface interactions misunderstood" by Lockart et al. Geophys. Res. Lett., 37, L10706, https://doi.org/10.1029/ 2009GL042254.

Carmona, A., G. Poveda, M. Sivapalan, S. Vallejo-Bernal, and E. Bustamante, 2016: A scaling approach to Budyko's framework and the complementary relationship of evapotranspiration in humid environments: Case study of the Amazon River basin. Hydrol. Earth Syst. Sci., 20, 589-603, https://doi.org/ 10.5194/hess-20-589-2016.

Chen, X., N. Alimohammadi, and D. Wang, 2013: Modeling interannual variability of seasonal evaporation and storage change based on the extended Budyko framework. Water Resour. Res., 49, 6067-6078, https://doi.org/10.1002/ wrcr.20493.

Cheng, L., Z. Xu, D. Wang, and X. Cai, 2011: Assessing interannual variability of evapotranspiration at the catchment scale using satellite-based evapotranspiration data sets. Water Resour. Res., 47, W09509, https://doi.org/10.1029/2011WR010636.

Chiew, F. H. S., M. C. Peel, and A. W. Western, 2002: Application and testing of the simple rainfall-runoff model SIMHYD. Mathematical Models of Small Watershed Hydrology and Applications, V. P. Singh and D. K. Frevert, Eds., Water Resources Publications, 335-367.
Donohue, R., M. Roderick, and T. R. McVicar, 2007: On the importance of including vegetation dynamics in Budyko's hydrological model. Hydrol. Earth Syst. Sci., 11, 983-995, https:// doi.org/10.5194/hess-11-983-2007.

, and _ 2010: Can dynamic vegetation information improve the accuracy of Budyko's hydrological model? J. Hydrol., 390, 23-34, https://doi.org/10.1016/j.jhydrol.2010.06.025.

,-- , and $\longrightarrow, 2012$ : Roots, storms and soil pores: Incorporating key ecohydrological processes into Budyko's hydrological model. J. Hydrol., 436-437, 35-50, https://doi.org/ 10.1016/j.jhydrol.2012.02.033.

Freund, E. R., and J. W. Kirchner, 2017: A Budyko framework for estimating how spatial heterogeneity and lateral moisture redistribution affect average evapotranspiration rates as seen from the atmosphere. Hydrol. Earth Syst. Sci., 21, 217-233, https://doi.org/10.5194/hess-21-217-2017.

Fu, B., 1981: On the calculation of the evaporation from land surface. Sci. Atmos. Sin., 5(1), 23-31.

Gentine, P., P. D'Odorico, B. R. Lintner, G. Sivandran, and G. Salvucci, 2012: Interdependence of climate, soil, and vegetation as constrained by the Budyko curve. Geophys. Res. Lett., 39, L19404, https://doi.org/10.1029/2012GL053492.

Gudmundsson, L., P. Greve, and S. I. Seneviratne, 2016: The sensitivity of water availability to changes in the aridity index and other factors-A probabilistic analysis in the Budyko space. Geophys. Res. Lett., 43, 6985-6994, https://doi.org/ 10.1002/2016GL069763.

Istanbulluoglu, E., T. Wang, O. M. Wright, and J. D. Lenters, 2012: Interpretation of hydrologic trends from a water balance perspective: The role of groundwater storage in the Budyko hypothesis. Water Resour. Res., 48, W00H16, https://doi.org/ 10.1029/2010WR010100.

Kistenmacher, M., and A. P. Georgakakos, 2015: Assessment of reservoir system variable forecasts. Water Resour. Res., 51, 3437-3458, https://doi.org/10.1002/2014WR016564.

Kumar, P., 2011: Typology of hydrologic predictability. Water Resour Res., 47, W00H05, https://doi.org/10.1029/2010WR009769.

Kumar, S., F. Zwiers, P. A. Dirmeyer, D. M. Lawrence, R. Shrestha, and A. T. Werner, 2016: Terrestrial contribution to the heterogeneity in hydrological changes under global warming. Water Resour. Res., 52, 3127-3142, https://doi.org/ 10.1002/2016WR018607.

Leuning, R., Y. Q. Zhang, A. Rajaud, H. Cleugh, and K. Tu, 2008: A simple surface conductance model to estimate regional evaporation using MODIS leaf area index and the PenmanMonteith equation. Water Resour. Res., 44, 652-655, https:// doi.org/10.1029/2007WR006562.

Li, D., M. Pan, Z. Cong, L. Zhang, and E. Wood, 2013: Vegetation control on water and energy balance within the Budyko framework. Water Resour. Res., 49, 969-976, https://doi.org/ 10.1002/wrcr.20107.

Liang, W., and Coauthors, 2015: Quantifying the impacts of climate change and ecological restoration on streamflow changes based on a Budyko hydrological model in China's Loess Plateau. Water Resour. Res., 51, 6500-6519, https://doi.org/ 10.1002/2014WR016589.

Livneh, B., J. S. Deems, D. Schneider, J. J. Barsugli, and N. P. Molotch, 2014: Filling in the gaps: Inferring spatially distributed precipitation from gauge observations over complex terrain. Water Resour. Res., 50, 8589-8610, https://doi.org/ 10.1002/2014WR015442.

Maurer, E. P., D. P. Lettenmaier, and N. J. Mantua, 2004: Variability and potential sources of predictability of North 
American runoff. Water Resour. Res., 40, W09306, https:// doi.org/10.1029/2003WR002789.

Milly, P., and K. Dunne, 2002: Macroscale water fluxes: 2. Water and energy supply control of their interannual variability. Water Resour. Res., 38, 1206, https://doi.org/ 10.1029/2001WR000760.

Oki, T., and S. Kanae, 2006: Global hydrological cycles and world water resources. Science, 313, 1068-1072, https://doi.org/ 10.1126/science. 1128845 .

Ol'Dekop, E. M., 1911: On evaporation from the surface of river basins (in Russian). Trans. Meteor. Obs., 4, 200.

Patterson, L. A., B. Lutz, and M. W. Doyle, 2013: Climate and direct human contributions to changes in mean annual streamflow in the South Atlantic, USA. Water Resour. Res. 49, 7278-7291, https://doi.org/10.1002/2013WR014618.

Peel, M. C., T. A. McMahon, B. L. Finlayson, and F. G. Watson, 2001: Identification and explanation of continental differences in the variability of annual runoff. J. Hydrol., 250, 224-240, https://doi.org/10.1016/S0022-1694(01)00438-3.

,-- , and -2004 : Continental differences in the variability of annual runoff-update and reassessment. J. Hydrol., 295, 185-197, https://doi.org/10.1016/j.jhydrol.2004.03.004.

Renner, M., and C. Bernhofer, 2012: Applying simple waterenergy balance frameworks to predict the climate sensitivity of streamflow over the continental United States. Hydrol. Earth Syst. Sci., 16, 2531-2546, https://doi.org/ 10.5194/hess-16-2531-2012.

Rheinheimer, D. E., R. C. Bales, C. A. Oroza, J. R. Lund, and J. H. Viers, 2016: Valuing year-to-go hydrologic forecast improvements for a peaking hydropower system in the Sierra Nevada Water Resour. Res., 52, 3815-3828, https://doi.org/10.1002/ 2015WR018295.

Roderick, M. L., and G. D. Farquhar, 2011: A simple framework for relating variations in runoff to variations in climatic conditions and catchment properties. Water Resour. Res., 47, W00G07, https://doi.org/10.1029/2010WR009826.

Sankarasubramanian, A., and R. M. Vogel, 2002: Annual hydroclimatology of the United States. Water. Resour. Res., 38, 1083, https://doi.org/10.1029/2001WR000619.

Schreiber, P., 1904: Über die Beziehungen Zwischen dem Niederschlag und der Wasserführung der Flüsse in Mitteleuropa. Meteor. Z., 21 (10), 441-452.

Sivapalan, M., and Coauthors, 2003: IAHS Decade on Predictions in Ungauged Basins (PUB), 2003-2012: Shaping an exciting future for the hydrological sciences. Hydrol. Sci. J., 48, 857880, https://doi.org/10.1623/hysj.48.6.857.51421.

Sun, F., 2007: Study on watershed evapotranspiration based on the Budyko hypothesis. Ph.D. thesis, Tsinghua University, 147 pp.

Tekleab, S., S. Uhlenbrook, Y. Mohamed, H. Savenije, M. Temesgen, and J. Wenninger, 2011: Water balance modeling of Upper Blue Nile catchments using a top-down approach. Hydrol. Earth Syst. Sci., 15, 2179-2193, https:// doi.org/10.5194/hess-15-2179-2011.

Ukkola, A., and I. Prentice, 2013: A worldwide analysis of trends in water-balance evapotranspiration. Hydrol. Earth Syst. Sci., 17, 4177-4187, https://doi.org/10.5194/hess-17-4177-2013.

Vano, J. A., J. A. Foley, C. J. Kucharik, and M. T. Coe, 2008: Controls of climatic variability and land cover on land surface hydrology of northern Wisconsin, USA. J. Geophys. Res., 113, G04040, https://doi.org/10.1029/2007JG000681.
Vogel, R. M., U. Lall, X. Cai, B. Rajagopalan, P. K. Weiskel, R. P. Hooper, and N. C. Matalas, 2015: Hydrology: The interdisciplinary science of water. Water Resour. Res., 51, 4409-4430, https://doi.org/10.1002/2015WR017049.

Wagener, T., and Coauthors, 2010: The future of hydrology: An evolving science for a changing world. Water Resour. Res., 46, W05301, https://doi.org/10.1029/2009WR008906.

Wang, D., and M. Hejazi, 2011: Quantifying the relative contribution of the climate and direct human impacts on mean annual streamflow in the contiguous United States. Water Resour. Res., 47, W00J12, https://doi.org/10.1029/ 2010WR010283.

—_ and N. Alimohammadi, 2012: Responses of annual runoff, evaporation, and storage change to climate variability at the watershed scale. Water Resour. Res., 48, W05546, https://doi.org/10.1029/2011WR011444.

Wang, T., E. Istanbulluoglu, J. Lenters, and D. Scott, 2009: On the role of groundwater and soil texture in the regional water balance: An investigation of the Nebraska Sand Hills, USA. Water Resour. Res., 45, W10413, https://doi.org/10.1029/ 2009WR007733.

Xu, X., W. Liu, B. R. Scanlon, L. Zhang, and M. Pan, 2013: Local and global factors controlling water-energy balances within the Budyko framework. Geophys. Res. Lett., 40, 6123-6129, https://doi.org/10.1002/2013GL058324.

Yang, D., F. Sun, Z. Liu, Z. Cong, G. Ni, and Z. Lei, 2007: Analyzing spatial and temporal variability of annual waterenergy balance in nonhumid regions of China using the Budyko hypothesis. Water Resour. Res., 43 (4), W04426, https://doi.org/10.1029/2006WR005224.

Zeng, R., and X. Cai, 2015: Assessing the temporal variance of evapotranspiration considering climate and catchment storage factors. Adv. Water Resour., 79, 51-60, https://doi.org/10.1016/ j.advwatres.2015.02.008.

_, and _ 2016: Climatic and terrestrial storage control on evapotranspiration temporal variability: Analysis of river basins around the world. Geophys. Res. Lett., 43, 185-195, https://doi.org/10.1002/2015GL066470.

Zhang, L., W. Dawes, and G. Walker, 2001: Response of mean annual evapotranspiration to vegetation changes at catchment scale. Water Resour. Res., 37, 701-708, https://doi.org/10.1029/ 2000WR900325.

, K. Hickel, W. Dawes, F. H. Chiew, A. Western, and P. Briggs, 2004: A rational function approach for estimating mean annual evapotranspiration. Water Resour. Res., 40, W02502, https://doi.org/10.1029/2003WR002710.

_- N. N. Potter, K. Hickel, Y. Zhang, and Q. Shao, 2008: Water balance modeling over variable time scales based on the Budyko framework-Model development and testing. J. Hydrol., 360, 117-131, https://doi.org/10.1016/ j.jhydrol.2008.07.021.

Zhang, Y. Q., F. H. S. Chiew, L. Zhang, R. Leuning, and H. A. Cleugh, 2008: Estimating catchment evaporation and runoff using MODIS leaf area index and the PenmanMonteith equation. Water Resour. Res., 44, 2183-2188, https://doi.org/10.1029/2007WR006563.

, and Coauthors, 2012: Decadal trends in evaporation from global energy and water balances. J. Hydrometeor., 13, 379391, https://doi.org/10.1175/JHM-D-11-012.1. 